\title{
GENETIC STUDIES OF THE SYRIAN HAMSTER
}

\section{WHITE BAND}

ROY ROBINSON

St. Stephens Rood Nursery, Eoling, London, W.13

\section{INTRODUCTION}

Received 25.i.62

FIVE recessive mutant genes have so far been considered in the present series of studies on the Syrian hamster, Mesocricetus auratus. All five of the genes are concerned with modification of the wild type agouti coat colour and detailed descriptions of the various phenotypes produced by the genes, either singly or in combination, have been contributed by Robinson (1958, 1959a, 1962). One of these mutant genes engenders a characteristic type of spotting which has been described as piebald (Foote, 1949; Orsini, 1952). The white areas in the typical piebald animal are distributed erratically and are much broken up.

However, another form of white spotting has recently appeared in the Syrian hamster which differs both phenotypically and genetically from the piebald. Phenotypically, the white areas are produced more uniformly and are not broken up to the same extent as those of the piebald while, genetically, the new mutant gene is inherited as a dominant to the wild type (Robinson, 1960). The present report deals with the independency of the two types of white spotting and the extent to which the new spotting gene has been tested for chromosomal linkage with the other known mutants.

\section{DESCRIPTION OF MUTANT GENES}

A detailed account of the coat pigmentation of the wild type Syrian hamster may be found in Robinson ( 1958 ). In general, the coat colour is that of an agouti, although the colour is more rufescent than that found in the usual laboratory rodent (for example, in the mouse) and two dark streaks of eumelanin occur on the shoulders. The following mutations have been employed in the present experiments.

\section{(i) Cream}

The cream phenotype is produced by an allele for non-extension of black pigmentation and is conveniently symbolised by $e$. The coat colour varies in intensity from a straw-yellow to a rich apricot-yellow. Although eumelanism is removed from the hair fibres, some may be observed in the eye, the palpebrae, the dermis of the auricle, around the genitalia of both sexes and about the sub-costal sebaceous glands. In general, the amount of pigment present in these regions is comparable to that found in the normal, although there are exceptions (Robinson, 1959a). The action of the allele appears to be a suppression of eumelanism from the fur, with the dermal pigmentation being mainly unaffected (Robinson, 1958).

(ii) Ruby-eye dilute

The expression of ruby-eye is that typical of an eye and coat colour diluting gene. The eye is deficient in pigment and glows a rich ruby-red by reflected light while 
the coat colour is a bluish-fawn. The allele is symbolised by $r u$. The yellowish colour of the cream hamster is diluted by the allele to a pastel cream and, consequently, the genotype eeruru may be readily distinguished from the ordinary cream.

There has been a significant deficiency of ruru animals in every cross in which this gene has featured (Robinson, 1958, 1959a, 1961). The deficiency has been particularly discussed in the 1959 paper, where a significant sex difference in the relative viability was apparent between some of the data. The $r u$ gene also occurs in cross $\mathrm{X}$ of the present report but, surprisingly, while there is a deficiency of ruru animals, the deficiency does not assume significant proportions. Close scrutiny of the distribution of classes for this segregation disclosed that the number of ruru males was below expectation while the number of ruru females was above expectation. This difference between the sexes can be seen from table 2, entry no. 24. However, although the deficiency of ruru males is obvious, the deficiency is not statistically significant $\left(\chi^{2}{ }_{1}=3.23 ; P>0.05\right)$, possibly because of the smallness of the sample size. The segregation is thus consistent in displaying impaired viability for the males but inconsistent inasmuch as the females appear to be of normal viability.

\section{(iii) Piebald}

The white spotting produced by this gene is very irregular and the whole body surface may be a mixture of coloured and white areas. This effect is strikingly shown by the piebald animal on the right for plate $1 b$. The distribution of spotting is not without some regularity as the percentage of white increases. Low-grade animals have the white pattern restricted to the foreface and belly, while the highgrade have extensive white areas on the body. The presence of a white streak extending from the nose to between the eyes is a reliable index for distinguishing the piebald in either low or high-grade individuals. In general, the progression of white is in an anterio-posterior direction, with a tendency for a post-medial belt of white which is rarely complete. The allele has been designated by the symbol $s$.

Animals homozygous for piebald are of reduced general stamina. Customarily, the piebald is of lower viability than either the normal agouti or the ruby-eye (Robinson, 1959a). The piebald is also subjected to various developmental defects of the urino-genital system (Orsini, 1952; Bock, 1953; Foote, 1955) and of the lower vertebrae (Robinson, 1959a). The estimated viability at 21 days of age has been variously estimated at about 30 per cent. of normal. The viability values for the crosses of this communication ranged some 33 to 97 per cent. greater than this (see table 3). Only the largest of these higher estimates may differ significantly from the initial estimates of about 30 per cent., and this could be dubious in view of the variation present between the different crosses taken as a whole.

\section{(iv) White band}

This new mutant allele was discovered by a fancier in the United States during 1957, and stock carrying the gene was imported into Britain in 1959. The allele has been termed " white band " and has been symbolised by $B a$. Preliminary evidence has firmly establi hed that the allele is inherited as a dominant to the wild type (Robinson, 1960). Furthermore, the homozygote $B a B a$ is fully viable, as revealed by reasonablygood $3: \mathrm{I}$ ratios for the $\mathrm{F}_{2}$ generation of $\mathrm{F}_{1}$ matings of type $B a b a \times B a b a$. The heterozygote $B a b a$ is of normal viability also, and this is one of several items of difference between the piebald and white band. The decreased viability of the piebald is associated with a reduction in weight but no weight change has been observed for the white band.

The mutant gene derives its name from a band of white which, in most individuals, either completely or almost completely encircles the body. This very characteristic pattern is clearly shown by plate $\mathrm{I} a$. Plate $\mathrm{i} a$ shows the steady progression of the band as the amount of white area increases. However, the expression of white is variable and in a large proportion of animals the medial band may be partially or 
completely interrupted by a spinal stripe of coloured fur. This spinal stripe is incipient for the second from the left and the last hamster of plate $\mathrm{a} a$ but fully apparent for the white band hamster of plate $\mathrm{I} b$.

With increasing amounts of white the band becomes wider, the stomach becomes almost completely depigmented and the areas of coloured fur are restricted to the head, shoulders and lower hindquarters. It should be noted, in particular, that (a) the head rarely (if at all) has any white and that $(b)$ the white areas are not extensively intermingled with the coloured. These two features, under usual circumstances, distinguish the white band from the piebald. At birth, the auricle of the ears of a great many white band individuals are pink, but in adult animals only the basal portions remain depigmented. The more extensive the body pattern, the greater are the depigmented areas of the auricle. The ears usually commence to darken about the 2Ist to 28th day of age. No pigment may form in the prepuce of the male, nor in the perineum or surrounding areas of the female.

It has been observed that three of the mutant alleles appear to be associated with differences in temperament. If the behaviour of the agouti is taken as standard, the cream is a more placid individual (on the average) while the ruby-eye and piebald are more nervous and excitable (Robinson, 1958). The piebald is noticeably a more irascible animal than the ruby-eye. As regards behaviour or temperament, the white band gene does not appear to have any obvious effects. Therefore, a ranking scale of increasing nervousness for the mutants could be portrayed as cream $>$ normal agouti $\simeq$ white band $>$ ruby-eye $>$ piebald.

Plate $\mathrm{I} b$ shows the effect of the two genes alone and in combination with each other. The middle specimen exhibits features belonging to each type of spotting : a medial band of white which is normally absent from the piebald, and white on the foreface and brindled posterior, both of which are usually absent from the band. In these experiments, the genotype Bass has not been difficult to identify, primarily because of the facial markings, in the majority of animals. However, there is reason to suppose that the piebald gene $s$ may be epistatic to $B a$ in some cases where the amount of band is of a low grade. The evidence for this supposition emerges in a later section.

The two spotting alleles apparently interact ontogenically as evinced by the distribution of percentage of white spotting displayed by Bass. An analysis of the mean grade of white shown by the Baba, ss and Babass animals of cross VII has yielded an interesting conclusion. The three genotypes segregated against a common genetic background; thus, there is little reason to assume the presence of a bias due to modifying polygenes. The mean percentage grade of spotting for the three genotypes Baba, ss and Babass are $16.34 \pm 0.87,19.3^{8} \pm 1.62$ and $57.83 \pm 4.63$, respectively. The similarity of the mean values for the first two is probably due to a coincidence but the point at issue at this juncture is the sharp increase in the mean percentage of white covering the body surface of Babass individuals. The distribution of spotting in the Baba or ss phenotype is very different, being more restricted in the former. The mean percentage of coloured coat for $B a b a$ is 83.66 and, the percentage of this area which might be expected to be white due to the independent action of the $s$ gene in the typical Babass is 19.38 . Therefore, the total percentage of white exhibited by Babass would be expected to be within the region of 32.56 . However, the observed average area for Babass has been determined to be 57.83 per cent. The difference between expectation and observation is considerable and doubtless has significance. The saltatory increase appeared to be due to an increase in the width of the white band rather than to an increase in the amount of the more generalised piebald type of spotting (see plate $\mathrm{I} b$ on this point).

\section{TESTS FOR LINKAGE}

The white band allele has been incorporated into a series of crosses undertaken for the purpose of detecting the existence of possible 
linkage between the known mutants. All the mutant genes described above have been tested for linkage with each other. Full details of the nature of the four linkage mating types are shown by table I, together with the resultant progeny. The data of the latter table are arranged in table 2 to reveal the genes which may be tested, the linkage phases and the distribution of crossover and non-crossover classes. In addition to the conventional gene symbols, the symbols $Y$ and $X$ are employed to represent differential segments of the sex chromosomes. The segregation of a gene may display a sex association which could be interpreted as partial sex-linkage. For convenience of statistical analysis, $Y$ has been treated as a dominant gene. Similarly, the linkage phase known

TABLE 1

Mating types and resulting segregation

\begin{tabular}{|c|c|c|c|c|c|c|c|c|c|c|}
\hline Cross & Mating type & & $B a$ & $B a e$ & Bas & Baes & + & $e$ & $s$ & es \\
\hline VII & $B a++X /+e s X \times+e s Y /+e s X$ & $\begin{array}{l}\text { o } \\
0 \\
+\end{array}$ & $\begin{array}{l}21 \\
11\end{array}$ & $\begin{array}{l}11 \\
13\end{array}$ & $\begin{array}{l}4 \\
6\end{array}$ & $\begin{array}{l}5 \\
8\end{array}$ & $\begin{array}{l}18 \\
12\end{array}$ & $\begin{array}{r}8 \\
13\end{array}$ & $\begin{array}{r}7 \\
11\end{array}$ & $\begin{array}{r}13 \\
9\end{array}$ \\
\hline VIII & $\begin{array}{r}B a++Y /+e s X \times \\
B a++X \mid+e s X\end{array}$ & $\begin{array}{l}* \\
0 \\
+\end{array}$ & $\begin{array}{l}19 \\
13\end{array}$ & $\begin{array}{r}7 \\
12\end{array}$ & $\begin{array}{l}4 \\
0\end{array}$ & $\begin{array}{l}\circ \\
\circ\end{array}$ & $\begin{array}{l}7 \\
6\end{array}$ & $\begin{array}{l}4 \\
0\end{array}$ & $\begin{array}{l}3 \\
1\end{array}$ & $\begin{array}{l}0 \\
1\end{array}$ \\
\hline IX & $\begin{aligned} B a++Y /+e s X & \times \\
& +++X /+e s X\end{aligned}$ & ơ & $\begin{array}{l}42 \\
57\end{array}$ & $\begin{array}{l}16 \\
19\end{array}$ & $\begin{array}{l}3 \\
9\end{array}$ & $\begin{array}{l}1 \\
2\end{array}$ & $\begin{array}{l}64 \\
63\end{array}$ & $\begin{array}{l}17 \\
10\end{array}$ & $\begin{array}{l}10 \\
13\end{array}$ & $\begin{array}{l}1 \\
3\end{array}$ \\
\hline $\mathbf{x}$ & $\begin{aligned} & B a+++ Y \mid+ \text { erus } X \times \\
& B a+++X /+ \text { erus } X\end{aligned}$ & $\begin{array}{l}+ \\
+0 \\
+ \\
r u \\
r u \\
r u\end{array}$ & $\begin{array}{r}29 \\
25 \\
4 \\
10\end{array}$ & $\begin{array}{l}5 \\
4 \\
1 \\
4\end{array}$ & $\begin{array}{l}4 \\
3 \\
0 \\
1\end{array}$ & $\begin{array}{l}0 \\
0 \\
0 \\
1\end{array}$ & $\begin{array}{l}5 \\
6 \\
2 \\
1\end{array}$ & $\begin{array}{l}1 \\
1 \\
0 \\
0\end{array}$ & $\begin{array}{l}2 \\
1 \\
0 \\
0\end{array}$ & $\begin{array}{l}0 \\
1 \\
0 \\
0\end{array}$ \\
\hline
\end{tabular}

as coupling has been used to represent the two dominant genes in association, regardless of which is the actual wild type. All the progeny were classified at 2 I days of age on the bases of eye, ear and coat colour. The various phenotypes can be accurately distinguished at this age.

The estimation of the recombination fractions was accomplished by means of maximum likelihood functions of the phenotypic class expectation. The general procedure for the formulation of these has been outlined in the first two papers (Robinson, I958, I959a). The formulation was relatively straightforward for all of the present crosses, since no viability interaction between the genes was encountered which could affect one class differentially. Out of the four genes considered in this paper, only the piebald conferred a semi-inviability upon animals homozygous for it. The other three were of normal viability, at least up to the recording age of 21 days. The presence of the weakened viability for the piebald does not interfere with the computation of the likelihood scores since the inviability is apportioned over complementary crossover and non-crossover classes. However, the amount of statistical information per zygote is reduced. 
The estimated recombination fractions are tabulated in table 3 , together with the various estimates of the viability of piebald homozygotes for each cross. None of the 25 fractions shown in the table are significant in the sense of differing significantly from 0.5 , the value for independent assortment. The three most widely deviating recombination fractions are those for es (cross VII; $\chi_{1}^{2}=3.39$ ), es (cross VIII; $\left.\chi_{1}^{2}=3.58\right)$ and Bae (cross IX; $\left.\chi_{1}^{2}=3.64\right)$. The $\chi^{2}$ values for all

TABLE 2

Classification of segregation for linkage analysis

\begin{tabular}{|c|c|c|c|c|c|c|c|c|}
\hline \multirow{2}{*}{ Cross } & \multirow{2}{*}{$\begin{array}{l}\text { Mating } \\
\text { type }\end{array}$} & \multicolumn{2}{|c|}{ Loci } & \multicolumn{4}{|c|}{ Phenotypic class } & \multirow{2}{*}{ Total } \\
\hline & & $a$ & $b$ & $A B$ & $A b$ & $a B$ & $a b$ & \\
\hline VII & $\begin{array}{l}\mathrm{CBB} \\
\mathrm{CBB} \\
\mathrm{CBB}\end{array}$ & $\begin{array}{l}B a \\
B a \\
B a\end{array}$ & $\begin{array}{l}e \\
s \\
r\end{array}$ & $\begin{array}{l}42 \\
56 \\
62\end{array}$ & $\begin{array}{l}37 \\
23 \\
22\end{array}$ & $\begin{array}{l}48 \\
51 \\
45\end{array}$ & $\begin{array}{l}43 \\
40 \\
4^{1}\end{array}$ & $\begin{array}{l}170 \\
170 \\
170\end{array}$ \\
\hline VIII & $\begin{array}{l}\text { CII } \\
\text { CII } \\
\text { CIB } \\
\text { CII } \\
\text { CII } \\
\text { CIB }\end{array}$ & $\begin{array}{c}B a \\
B a \\
B a \\
e \\
e \\
s\end{array}$ & $\begin{array}{l}e \\
s \\
r \\
s \\
r \\
r\end{array}$ & $\begin{array}{l}36 \\
51 \\
30 \\
45 \\
33 \\
37\end{array}$ & $\begin{array}{r}19 \\
4 \\
25 \\
8 \\
20 \\
31\end{array}$ & $\begin{array}{r}17 \\
17 \\
14 \\
23 \\
11 \\
7\end{array}$ & $\begin{array}{r}5 \\
5 \\
8 \\
1 \\
13 \\
2\end{array}$ & $\begin{array}{l}77 \\
77 \\
77 \\
77 \\
77 \\
77\end{array}$ \\
\hline IX & $\begin{array}{l}\text { CBI } \\
\text { CBI } \\
\text { CBB } \\
\text { CII } \\
\text { CIB } \\
\text { CIB }\end{array}$ & $\begin{array}{c}B a \\
B a \\
B a \\
e \\
e \\
s\end{array}$ & $\begin{array}{l}e \\
s \\
r \\
s \\
r \\
r\end{array}$ & $\begin{array}{r}111 \\
134 \\
62 \\
226 \\
119 \\
139\end{array}$ & $\begin{array}{r}38 \\
15 \\
87 \\
61 \\
142 \\
149\end{array}$ & $\begin{array}{r}150 \\
154 \\
92 \\
34 \\
35 \\
15\end{array}$ & $\begin{array}{r}31 \\
27 \\
89 \\
7 \\
34 \\
27\end{array}$ & $\begin{array}{l}330 \\
330 \\
330 \\
330 \\
330 \\
330\end{array}$ \\
\hline $\mathrm{x}$ & $\begin{array}{l}\text { CII } \\
\text { CII } \\
\text { CII } \\
\text { CII } \\
\text { CII } \\
\text { CII } \\
\text { CIB } \\
\text { CII } \\
\text { CIB } \\
\text { CIB }\end{array}$ & $\begin{array}{c}B a \\
B a \\
B a \\
B a \\
e \\
e \\
e \\
r u \\
r u \\
s\end{array}$ & $\begin{array}{c}e \\
r u \\
s \\
r \\
r u \\
s \\
r \\
s \\
r \\
r\end{array}$ & $\begin{array}{l}76 \\
70 \\
82 \\
39 \\
75 \\
82 \\
43 \\
76 \\
43 \\
47\end{array}$ & $\begin{array}{r}15 \\
21 \\
9 \\
52 \\
18 \\
11 \\
50 \\
11 \\
44 \\
51\end{array}$ & $\begin{array}{r}17 \\
17 \\
16 \\
11 \\
12 \\
16 \\
7 \\
22 \\
7 \\
6\end{array}$ & $\begin{array}{r}3 \\
3 \\
4 \\
9 \\
6 \\
2 \\
11 \\
2 \\
2 \\
17 \\
7\end{array}$ & 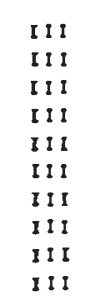 \\
\hline
\end{tabular}

three were sub-significant; furthermore, only the first showed a tendency towards infra-recombination as would be suggestive of linkage, the other two showed a tendency for supra-recombination. It is doubtful if these results have any special significance. It may be concluded that the $B a$ gene segregates independently of $e$ and $r u$. This conclusion is warranted, of course, for the data to hand. It is always possible, however, for $B a$ to be exceedingly loosely linked with one of these genes. A rough estimation of the permissible closeness of this linkage (with regard to sample size) is shown by the last column of table 4. With regard to the joint segregation of $B a$ with $s$, although 
the data from the individual crosses did not reveal the probability of linkage between the two genes, when the four groups of data were statistically combined, unmistakable evidence emerged for a fairly loose linkage. The heterogeneity between the various samples was negligible (but see the following section for a full account of the analysis).

TABLE 3

Estimated recombination fractions and viabilities

\begin{tabular}{|c|c|c|c|}
\hline Cross & Loci & Recombination fraction & Viability \\
\hline VII & $\begin{array}{l}B a-\varepsilon \\
B a-s \\
e-s\end{array}$ & $\begin{array}{l}0.5000 \pm 0.0384 \\
0.4353 \pm 0.0384 \\
0.4294 \pm 0.0384\end{array}$ & $\begin{array}{l}0.5888 \pm 0.0935 \\
0.5888 \pm 0.0935\end{array}$ \\
\hline VIII & $\begin{array}{l}B a-e \\
B a-s \\
B a-r \\
e-s \\
e-r \\
s-r\end{array}$ & $\begin{array}{l}0.55^{8} 4 \pm 0.0855 \\
0.3223 \pm 0.1064 \\
0.5^{8} 44 \pm 0.0987 \\
0.7013 \pm 0.1064 \\
0.3766 \pm 0.0987 \\
0.6667 \pm 0.1667\end{array}$ & $\begin{array}{l}0.3971 \pm 0.1409 \\
0.3971 \pm 0.1409 \\
0.3971 \pm 0.1409\end{array}$ \\
\hline IX & $\begin{array}{l}B a-e \\
B a-s \\
B a-Y \\
e-s \\
e-Y \\
s-Y\end{array}$ & $\begin{array}{l}0.5909 \pm 0.0477 \\
0.4640 \pm 0.0581 \\
0.5379 \pm 0.0276 \\
0.4955 \pm 0.0540 \\
0.5394 \pm 0.0477 \\
0.4414 \pm 0.5^{810}\end{array}$ & $\begin{array}{l}0.4375 \pm 0.0815 \\
0.4375 \pm 0.0815 \\
0.4375 \pm 0.0815\end{array}$ \\
\hline $\mathrm{X}$ & $\begin{array}{l}B a-e \\
B a-r u \\
B a-s \\
B a-r \\
e-r u \\
e-s \\
e-r \\
r u-s \\
r u-Y \\
s-Y\end{array}$ & $\begin{array}{l}0.4790 \pm 0.0822 \\
0.5484 \pm 0.0712 \\
0.3500 \pm 0.0886 \\
0.5856 \pm 0.0822 \\
0.4122 \pm 0.0712 \\
0.4337 \pm 0.0886 \\
0.4775 \pm 0.0822 \\
0.5175 \pm 0.0886 \\
0.3762 \pm 0.0822 \\
0.5070 \pm 0.1023\end{array}$ & $\begin{array}{l}0.3980 \pm 0.1167 \\
0.3980 \pm 0.1167 \\
0.3980 \pm 0.1167 \\
0.3980 \pm 0.1167\end{array}$ \\
\hline
\end{tabular}

\section{COMBINATION OF DATA}

A very considerable advantage of the system of scoring by maximum likelihood functions is that separate samples may be amalgamated to form a single estimate of the recombination fraction. The data from the four crosses described have been combined in this way. For most of the pairs of genes examined for linkage, the combination has yielded negative results but for one pair the results are not negative. The two genes were the $B a$ and $s$. While the analyses for each of the crosses did not exceed the conventional levels of statistical significance, the combined estimate did so. The $\chi_{1}^{2}$ for the departure from random assortment of the two genes is 6.72 and is significant $(\mathrm{P}<0.0 \mathrm{I})$. The heterogeneity between the four crosses is insignificant $\left(\chi_{3}^{2}=2 \cdot 16\right.$, $\mathrm{P} \simeq 0.5)$. The four segregations, therefore, are homogeneous in showing an apparent loose linkage between the genes $B a$ and $s$. The final estimate of the recombination fraction is $p=0.4275 \pm 0.028 \mathrm{I}$. 
For this value, the amount of heterogeneity between the four samples is trivial $\left(\chi_{3}^{2}=1 \cdot 69, P \simeq 0 \cdot 7\right)$.

Unfortunately, the evidence for linkage between the two genes is not entirely conclusive. Examination of the four Bas segregations of table 2 discloses that the two non-piebald classes do not differ greatly from expectation. The main support for the existence of linkage is derived from a deficiency of Bass (crossovers) and a surplus of $++s s$ (non-crossover) animals. This unbalance of the two piebald class frequencies could occur if the erratic pattern of $s$ was epistatic to the more regular pattern of $B a$. If the white band produced by $B a$ was extensive, complete epistasis by $s$ would be improbable (if not impossible), but should the band be small or merely half-formed, then an epistatic relation of $s$ to $B a$ is only too probable. This explanation for the disturbed simultaneous segregations of $B a$ and $s$ is too likely to be dismissed. A further alternative explanation would be that the Bass individual is semi-inviable (perhaps as a consequence of an interaction of the two genes) but this explanation cannot readily account for the small surplus of $++s s$ animals. It must be remembered that $s s$ animals are only about 30 to 40 per cent. viable, yet the $++s s$ class is well up to expectation. A clear distinction between $(a)$ the possibility of a weak linkage between $B a$ and $s$ or $(b)$ epistasis of $s$ over $B a$ in a proportion of animals, will probably remain undecided until data becomes available which is in opposite linkage phase to those reported in this paper.

At the present time, ten crosses yielding useful information on the possibility of linkage have been completed and the results analysed. The same pairs of genes have featured in many of these crosses and the amalgamation has enabled a much more precise estimation to be made of the recombination fraction. The combination was achieved by summing the score and information for a crossover value of 0.5 or supposedly independent segregation. The standard error of the estimate was also computed for the same value.

A summary of the statistical results of the data combination is presented in table 4. The first two columns of the table show the two gene loci compared and the joint estimate of the recombination fraction. The summed scores and total information are included for their usefulness for future amalgamations. Column five is an index of phase balance, a quantity tabulated as the percentage of the total information contributed by segregation in the coupling phase of linkage. Perfect balance would be shown by an index of 50, a value which possesses the implication that certain inviability interactions between genotypes (which could bias the results) are on the average cancelled out. The final column in the table presents an approximate estimate of the closest linkage consistent with the sample size. For convenience, this is computed as $0 \cdot 5-1 \cdot 96(s)$, where $s$ is the standard error of the relevant recombination fraction. At this juncture, it is not considered worthwhile to strive for a more accurate approximation. 
It may be observed that the entry in the table for ruY is formally significant. However, it is extremely doubtful if this is indicative of linkage. The significant value has arisen because of the differential sex viability of ruru animals and the relatively greater deficiency of ruru males. The ruru males form a crossover class and the relatively greater deficiency shows up in the analysis as a lack of crossovers. This differential viability has been consistently maintained throughout the various crosses and has been analysed thoroughly elsewhere (Robinson, 1959a). Reference should be made to this account. As a last note on this point, the two non-ruby-eye classes of the segregation

TABLE 4

Summary of extent of linkage tests in the Syrian hamster

\begin{tabular}{|c|c|c|c|c|c|}
\hline Loci & $\begin{array}{c}\text { Recombination } \\
\text { fraction }\end{array}$ & Score & $\begin{array}{c}\text { Total } \\
\text { information }\end{array}$ & $\begin{array}{c}\text { Phase } \\
\text { balance }\end{array}$ & $\begin{array}{l}\text { Closest } \\
\text { linkage }\end{array}$ \\
\hline $\begin{array}{l}b-e . \\
b-r u . \\
b-Y . \\
B a-e . \\
B a-r u \\
B a-r \\
c^{d}-e . \\
c^{d}-r u \\
c^{d-s} . \\
c^{d}-r . \\
e-r u \\
e-s: \\
e-r . \\
r u-Y . \\
s-Y .\end{array}$ & $\begin{array}{l}0.50 \pm 0.04 \\
0.51 \pm 0.04 \\
0.56 \pm 0.04 \\
0.53 \pm 0.03 \\
0.55 \pm 0.07 \\
0.55 \pm 0.03 \\
0.52 \pm 0.03 \\
0.47 \pm 0.03 \\
0.41 \pm 0.08 \\
0.52 \pm 0.02 \\
0.47 \pm 0.02 \\
0.48 \pm 0.02 \\
0.50 \pm 0.02 \\
0.47 \pm 0.02 \\
0.50 \pm 0.03\end{array}$ & $\begin{array}{c}\mathrm{I} \cdot 3333 \\
3 \\
34 \\
44.8889 \\
9.5556 \\
7 \mathrm{I} \cdot 3334 \\
20.88889 \\
-24.9835 \\
-12.8133 \\
6 \mathrm{I} \cdot 9999 \\
-104.3333 \\
-57.5555 \\
-12.6667 \\
-137^{*} \\
0\end{array}$ & $\begin{array}{r}733 \cdot 3333 \\
599 \cdot 0820 \\
580 \\
1404 \cdot 8889 \\
197 \cdot 3333 \\
1570 \cdot 6667 \\
930 \cdot 9622 \\
938 \cdot 1825 \\
138.0122 \\
2793.3333 \\
3965 \cdot 0066 \\
2571 \cdot 5192 \\
4524 \cdot 8743 \\
3979 \cdot 2816 \\
1455.9830\end{array}$ & $\begin{array}{r}0 \\
0 \\
100 \\
100 \\
100 \\
100 \\
0 \\
0 \\
100 \\
0 \\
81 \\
81 \\
86 \\
100 \\
29\end{array}$ & $\begin{array}{l}0.43 \\
0.42 \\
0 \cdot 42 \\
0.45 \\
0.36 \\
0 \cdot 45 \\
0.44 \\
0.44 \\
0.34 \\
0.46 \\
0.47 \\
0.46 \\
0.47 \\
0.47 \\
0.45\end{array}$ \\
\hline
\end{tabular}

* Significant; see text.

(table 2, entry 24) display no disturbance from expectation $\left(\chi_{1}^{2}=0.01\right.$, $\mathrm{P} \simeq 0 \cdot 95)$. This question could, of course, be easily settled by arranging for a series of matings in opposite linkage to those so far obtained but the complete or almost complete sterility of the ruby-eye male (Bruce, 1959) has prevented this to date.

The symbol $b$ of table 4 represents a recently investigated colour variant for brown eumelanism. The $b b$ animal is known as cinnamon and possesses a bright orange-cinnamon coat. A full account of work with this mutant allele has been presented elsewhere (Robinson, 1962).

\section{DISCUSSION}

This report describes another gene to add to the growing list of mutant alleles in the hamster. It is also the fourth instalment of a search for possible linkage between the various known alleles. Thus far, six alleles have been studied, albeit incompletely. A concise summary of the various pairs of genes which have been tested against 
each other is provided by table 4 . It may be seen that nine pairs have been studied out of the possible 15 combinations. All of the genes have been examined for partial sex-linkage, although positive results were scarcely to be anticipated. Not one of the nine combinations so far investigated has given any hint of a linkage. It is always possible, of course, that one or more of the pairs are loosely linked, although doubtless the odds are against the possibility.

Two pairs of genes have produced disturbed joint segregations which may be indicative of linkage. The first of these were the gene pair $r u-s$ but the situation created by this pair has been partially resolved (Robinson, 1959b). It is reasonably certain that the observed departure from random assortment was due to an inviability interaction between the genes. The second couple of genes with apparent non-random segregation is the pair $B a-s$, the data of which are presented in this paper. Although the two may reside in a common segment of chromosome, it may nevertheless be argued that the observed departure from independent assortment on the phenotypic level may be due to confusion of a small number of $B a-s s$ animals with $++s s$ in those cases where the expression of white band is of a low order. That is, the joint segregation of the two genes is disturbed by epistasis. This situation still awaits definite resolution.

\section{SUMMARY}

I. A new mutant allele, white band, is described and tested for linkage with other known genes of the Syrian hamster.

2. The new gene is inherited as a dominant and produces a typical band of white encircling the trunk.

3. The simultaneous segregation of white band and piebald (a recessive spotting gene) is distorted from that expected for independency. If the two genes are linked, the recombination fraction is of the order of $0.4275+0.0281$. Unfortunately, the evidence for linkage is not conclusive, for the disturbed class frequencies could be produced by a minor epistatic relation between the two genes.

4. A summary is included of all linkage tests so far completed for six mutants of the hamster.

Acknowledgment.-I wish to thank Mrs Margaret Beher for her kindness in sending me specimens of white band hamsters.

\section{REFERENCES}

воск, м. 1953. Urogenital-anomalien bei geschekten goldhamstern. Z. Naturfoschg., $8 b, 669-672$.

BRUCE, H. M. 1958. Genetic infertility in ruby-eye male hamsters. Studies in Fertility, 9, 90-98.

Foote, c. L. 1949. A mutation in the golden hamster. F. Hered., $40,101$.

FоOTE, C. L. 1955. Urogenital abnormalities in the golden hamster. Anat. Rec., I2I, $83 I-842$. 
orsini, M. W. I952. The piebald hamster. F. Hered., 43, 37-40.

ROBINSON, R. I958. Genetic studies of the Syrian hamster. I. The mutant genes cream, ruby-eye and piebald. $\mathcal{F}$. Genet., 56, 85-102.

Robinson, R. I959a. Genetic studies of the Syrian hamster. II. Partial albinism. Heredity, $13,165-177$.

ROBINSON, R. I959b. Genetic independency of four mutants in the Syrian hamster. Nature, 183 , I 25-1 26.

ROBINSON, R. I96o. White band, a new spotting mutation in the Syrian hamster. Nature, $188,764-765$.

ROBINSON, R. I962. Genetic studies of the Syrian hamster. IV. Brown pigmentation. Genetica (in press). 

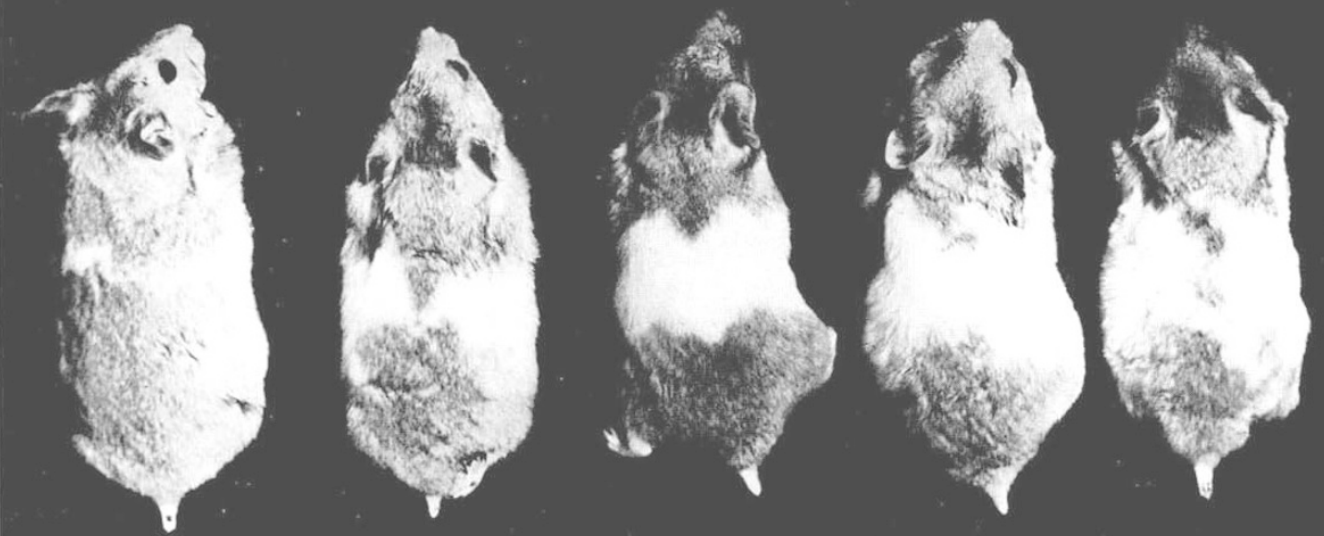

Plate Ia

Variation of expression of dominant white band spotting.

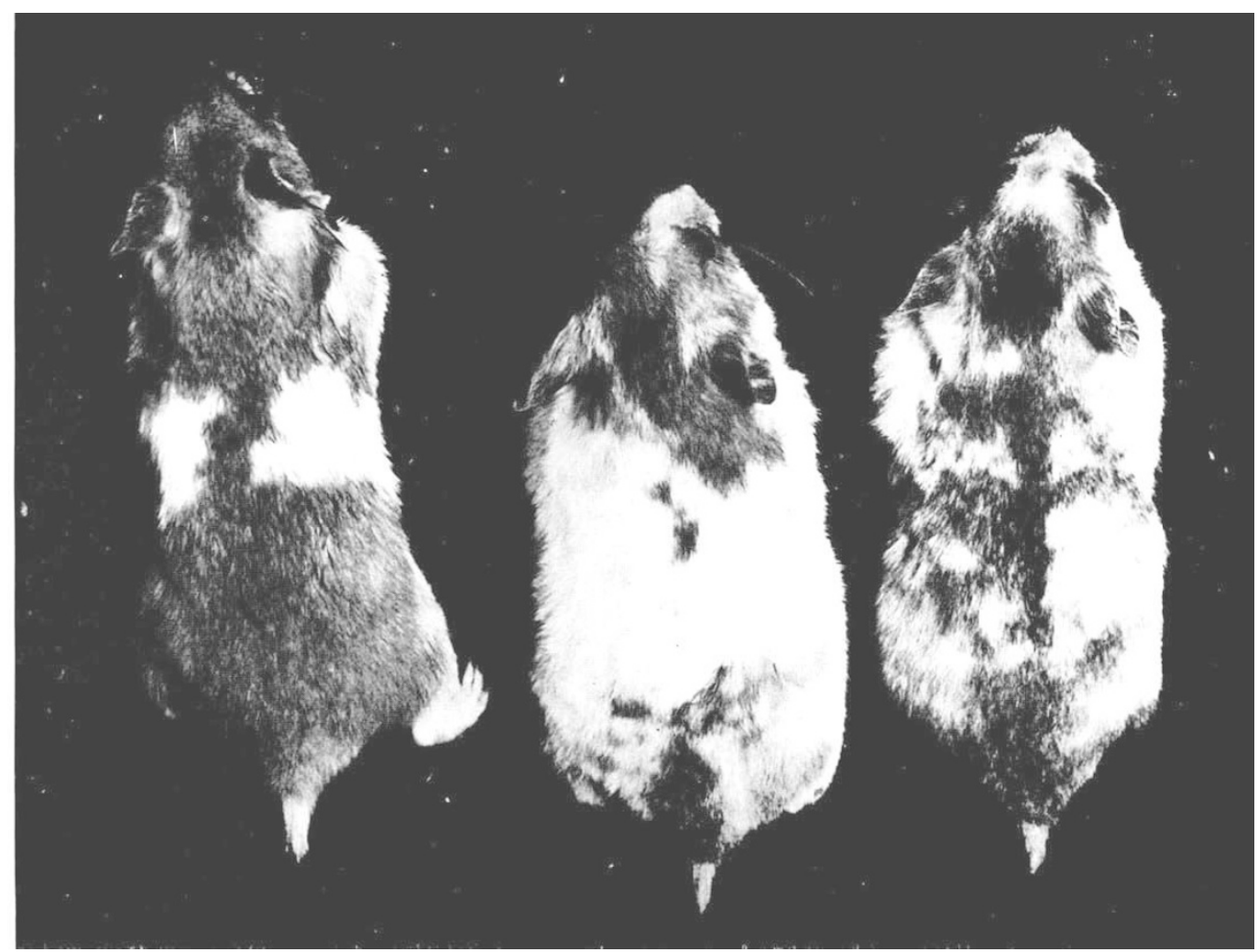

Plate $\mathrm{Ib}$

The two types of white spotting : white band (left) and piebald (right). The centre animal is genetically both white band and piebald. The almost independent action of each allele may be observed in this individual. All three individuals are typical of their type. 